\title{
A Novel Thin Film Dispenser Cathode for Thermionic Emission
}

\author{
K.R. Zavadil, D.B. King and J.A. Ruffner \\ Sandia National Laboratories, Albuquerque, NM 87185-0888 \\ (505) 845-8442; krzavad@sandia.gov
}

\begin{abstract}
A thin film dispenser or micro-dispenser cathode can be generated using standard rf sputtering deposition technology. These films are compositionally modulated structures based on $\mathrm{W}$ and a multi-component Ba oxide. Annealing to temperatures from 900 to $1300 \mathrm{~K}$ results in Ba reduction, transport and diffusion across the emitter surface. A finite temperature range exists $(<1200 \mathrm{~K})$ where a uniform Re coating can be retained at the emitter surface. The metallic coating results in a nearly homogeneous work function based on emission characteristics. These films produce stable emission at higher temperatures $(\geq 1200 \mathrm{~K})$ where the uniform Re coating is lost. Analysis of emission properties yield a work function of $2.2 \mathrm{eV}$ and an apparent emission coefficient of $6 \mathrm{~A} \cdot \mathrm{cm}^{-2} \cdot \mathrm{K}^{-2}$ after annealing to $1200 \mathrm{~K}$. This high apparent emission coefficient yields a film suitable for milliwatt power generation applications. Microminiature Thermionic Converters (MTCs) are one potential application for these films.
\end{abstract}

\section{INTRODUCTION}

Several technologies require a method of integrating a thin, electron emissive film into an energy generating or conversion device. Examples include miniature thermionic diodes (King, 2000) used as small-scale power sources and high frequency microwave generators (klystrons) for particle acceleration or directed energy applications. The electron source community has optimized macroscopic cathodes based on impregnating a porous tungsten matrix with barium oxide for display applications (Thomas, 1990). Their thin film work has been isolated to modification of these macrostructures to improve cathode lifetime (Gibson, 1989 and Gärtner, 1997). The power and acceleration communities have relied on slurry-based techniques to deposit mixed oxide films. This approach results in considerable effort spent in activating and conditioning the films prior to stable use. We report on a method of generating low work function, electron emissive films based on the materials system used by the display industry. These films are essentially micro-dispensers that are deposited as a monolithic structure using rf sputtering.

\section{EXPERIMENTAL}

Thin cathode films are deposited using rf sputtering. Deposition is conducted in a Unifilm PVD300 system with both substrate translation and rotation to ensure better than $98 \%$ film thickness uniformity over a 4 inch diameter. Emitter devices are deposited in arrays onto a single substrate using shadow masks to define structures. Aluminum nitride or sapphire is used as a high thermal conductivity substrate on which the emitter, electrode structure and resistive heater are deposited. Ta or $\mathrm{Pt}(400 \mathrm{~nm})$ is used as the base electrode film with a thin $(5 \mathrm{~nm}) \mathrm{Ti}$ under layer to ensure bonding integrity to the substrate at elevated temperatures. The emitter is some composition of $\mathrm{BaCaAlO}_{\mathrm{x}}$, $\mathrm{Sc}_{2} \mathrm{O}_{3}$ and $\mathrm{W}$ depending on the desired film composition. $\mathrm{BaSrCaO}_{x}$ has also been used as an alternate oxide layer. The mixed oxides are deposited from single targets with compositions (mole fraction) of 4:1:1 and 47.5:47.5:5 $\mathrm{Ba}: \mathrm{Ca}: \mathrm{Al}$ and $\mathrm{Ba}: \mathrm{Sr}: \mathrm{Ca}$, respectively. The $\mathrm{W}$ and mixed oxide films are deposited sequentially in a modulated or layered structure with a relative thickness and period dependent on desired properties. Select surface termination layers are also deposited to tailor emission properties. Both substrate temperature and plasma pressure are varied to tailor the porosity of the resulting films. 


\section{DISCLAIMER}

This report was prepared as an account of work sponsored by an agency of the United States Government. Neither the United States Government nor any agency thereof, nor any of their employees, make any warranty, express or implied, or assumes any legal liability or responsibility for the accuracy, completeness, or usefulness of any information, apparatus, product, or process disclosed, or represents that its use would not infringe privately owned rights. Reference herein to any specific commercial product, process, or service by trade name, trademark, manufacturer, or otherwise does not necessarily constitute or imply its endorsement, recommendation, or favoring by the United States Government or any agency thereof. The views and opinions of authors expressed herein do not necessarily state or reflect those of the United States Government or any agency thereof. 


\section{DISCLAIMER}

Portions of this document may be illegible in electronic image products. Images are produced from the best available original document. 
Emission testing is conducted in an ultrahigh vacuum system maintained at a base pressure of less than $1 \times 10^{-7} \mathrm{~Pa}$. The emitter is resistively heated by passing current through a $600 \mathrm{~nm}$ Ta film deposited on the back of the substrate. $\mathrm{Pd}$ wire is bonded to the emitter electrode structure to establish electrical connection to the cathode. This emitter is mounted on a manipulator that can be translated to various positions within the vacuum chamber. A molybdenum electrode, of equivalent dimensions to the cathode, serves as a collector for emission tests. This collector is mounted on a second micrometer driven manipulator providing for an adjustable inter-electrode gap down to $10 \mu \mathrm{m}$ in dimension. The gap distance is measured by noting the position of electrical contact with the emitter and retracting the collector a measured distance. A Keithley 237 source-measure unit is used for electrode potential control and current measurement. Emission is generally evaluated at a 100 to $150 \mu \mathrm{m}$ gap spacing. Surface composition is tracked by translation of the sample to the focal point of a Physical Electronics 12-150 cylindrical mirror analyzer and conducting Auger electron spectroscopy. Beam currents are kept to less than $1 \mu \mathrm{A} \cdot \mathrm{cm}^{-2}$ to minimize stimulated desorptive damage to the films.

\section{RESULTS AND DISCUSSION}

A highly intermixed, porous film results with heating a compositionally modulated $\mathrm{W} / \mathrm{BaCaAlO}$ film to moderate temperatures. Figure 1 shows backscattered electron images of a $10 \mathrm{~nm}$ W/20 nm BaCaAlO ${ }_{x}$ film as-deposited (a) and after annealing to $1300 \mathrm{~K}$ (b). This film is terminated with a $3.5 \mathrm{~nm} \mathrm{Re} / 2 \mathrm{~nm} \mathrm{Sc} \mathrm{S}_{2}$ layer. The alternating light and dark bands in the as-deposited film correspond to $\mathrm{W}$ and $\mathrm{BaCaAlO}_{\mathrm{x}}$, respectively. The terminating layer is not seen in these images because its thickness is only a fraction of the $\mathrm{W}$ or $\mathrm{BaCaAlO}_{\mathrm{x}}$ interlayer thickness. Well resolved bands are dominant in the as-deposited material while additional structure appears with annealing. Annealing produces apparent coalescence of the $\mathrm{W}$ resulting in voids distributed along the original $\mathrm{W}$ layers. These voids are visible as dark spots in Figure 1b. These voids may represent possible pathways for facile transport of free $\mathrm{Ba}\left(\mathrm{Ba}^{\circ}\right)$ to the emitter surface. This level of structural modification in the film does not appear to drive surface morphological changes. Atomic force and scanning electron microscopy conducted on samples known to retain a uniform Re coating up to $1300 \mathrm{~K}$ show that the as-deposited surface morphology is largely unchanged.

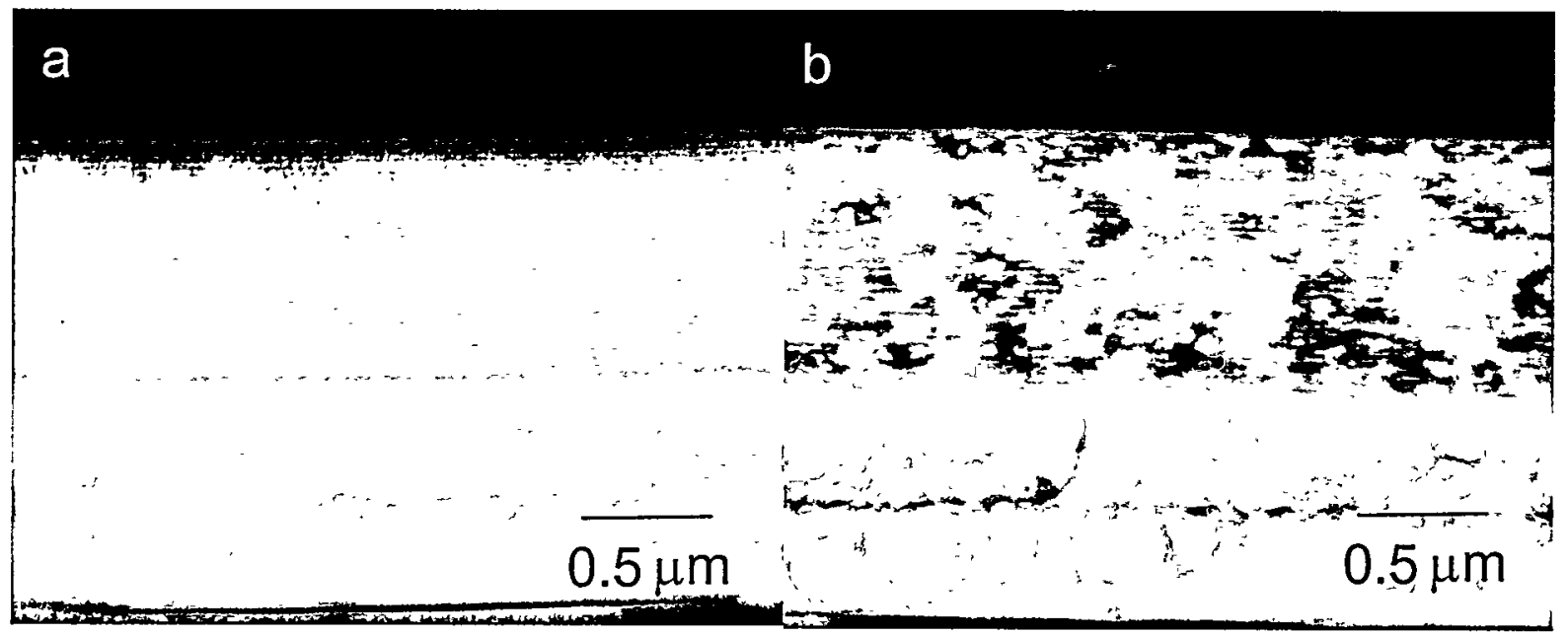

FIGURE 1. Backscattered electron images of a $1 \mu \mathrm{m}$ thick compositionally modulated film - a) as-deposited and b) annealed to $1300 \mathrm{~K}$. The film appears in the upper portion of the micrograph (banded region) and is comprised of alternating $10 \mathrm{~nm} \mathrm{~W}$ (light) and $20 \mathrm{~nm} \mathrm{BaCaAlO}$ layers (dark) with a $3.5 \mathrm{~nm} \mathrm{Re} / 2 \mathrm{~nm} \mathrm{Sc}_{2} \mathrm{O}_{3}$ terminating layer (not visible). The thick bright bands below the modulated film are the metal electrode layers.

The process of $\mathrm{W}$ coalescence with film annealing is experimentally confirmed using $\mathrm{x}$-ray diffraction. Figure 2 shows a series of diffraction spectra acquired at a $2^{\circ}$ grazing incidence angle while annealing a $10 \mathrm{~nm}$ W/10 nm $\mathrm{BaSrCaO}_{x}$ modulated film from 298 to $1300 \mathrm{~K}$. The data show that the original $10 \mathrm{~nm} \mathrm{~W}$ interlayers do not produce a coherent diffraction feature. Annealing the film produces a feature at $40.3^{\circ}$ below $1000 \mathrm{~K}$ that continues to grow in intensity and narrow in width. These observations are consistent with the coalescence of $W$ particles. $W$ coalescence is preceded at $900 \mathrm{~K}$ by the appearance of an intense feature at $28.5^{\circ}$. This peak is consistent with a $\mathrm{Ba}, \mathrm{Sr}$ or mixed tungstate $\left(\mathrm{WO}_{\mathrm{x}}{ }^{\mathrm{n}-}\right)$ phase. The presence of the tungstate signals the reduction of $\mathrm{Ba}^{2+}$ in the rriginal oxide as some tis 
fraction of $\mathrm{W}$ becomes oxidized. This data demonstrates that the mechanisms used for Ba generation and transport in macro-dispenser cathodes can also be built into thin film structures.

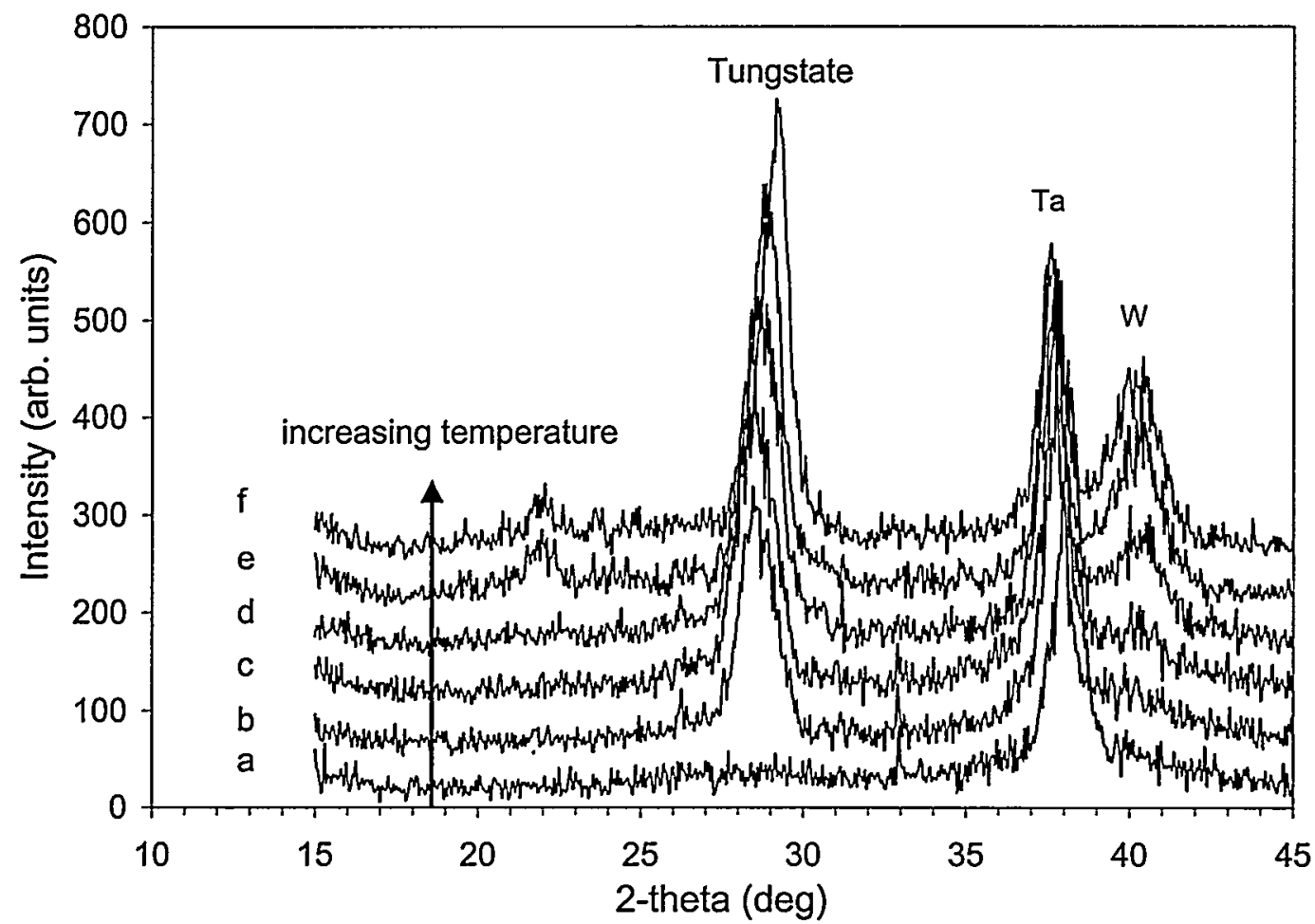

FIGURE 2. Grazing Angle $\left(2^{\circ}\right)$ Incidence X-ray Diffraction spectra of a $10 \mathrm{~nm} \mathrm{W/20} \mathrm{nm} \mathrm{BaSrCaO}$ modulated film as a function of annealing temperature - a) 298 , b) 900 , c) 1000 , d) 1100 , e) 1200 , and f) $1300 \mathrm{~K}$.

$\mathrm{Ba}$ is transported to the surface of the compositionally modulated films at moderate temperatures. Figure 3 shows the relative surface concentrations, as determined by Auger electron spectroscopy, with increased annealing temperature of the film. This data was acquired over a 14 hour time period with holds at individual temperatures ranging from 30 minutes to 3 hours. Initial levels of near-surface $\mathrm{Ba}$ and $\mathrm{O}$ are less than 11 and 5 atomic percent respectively and result from sampling the first $\mathrm{BaCaAlO}_{\mathrm{x}}$ layer beneath the $3.5 \mathrm{~nm} \mathrm{Re} / 2 \mathrm{~nm} \mathrm{Sc} \mathrm{O}_{3}$ terminating layer. $\mathrm{Ba}$ and $\mathrm{O}$ signals start to increase below $900 \mathrm{~K}$ and saturate above $1000 \mathrm{~K}$. These increases correlate with decreased $\mathrm{Re}$ indicating that either $\mathrm{Ba}$ and $\mathrm{O}$ transport to the surface and then diffuse laterally covering the Re surface or that $\mathrm{Re}$ starts to cluster on the surface exposing the underlying $\mathrm{BaCaAlO}_{x}$ layer. Large scale Re nucleation can be eliminated as a possibility because no measurable increase in Ca signal is observed. It is interesting to note that $\mathrm{Sc}$ does not appear to move toward the surface during this transport process. Scandium appears to play a key role in establishing a favorable surface dipole for emission (Zagwijn, 1997). It appears as if Sc is not being utilized in this film. The oscillation in the Re signal observed from 870 to $1000 \mathrm{~K}$ appears to be the result of $\mathrm{CO} / \mathrm{CO}_{2}$ adsorption onto Re sites, and subsequent signal reduction due to electron scattering, as evidenced by a corresponding oscillation in $\mathrm{C}$ signal (not shown). The fact that $\mathrm{Re}$ is available for adsorption suggests that complete $\mathrm{Ba}$ coverage does not occur. Both $\mathrm{CO}$ and $\mathrm{CO}_{2}$ are observed in mass spectrometric measurements conducted during annealing. These results demonstrate that this type of film becomes activated for electron emission at temperatures as low as $900 \mathrm{~K}$ and that a $\mathrm{Ba} / \mathrm{O}$ modified Re terminating layer is the surface responsible for emission.

Electron emission measurements show that annealing these compositionally modulated films produces a low work function, emissive surface. Figure 4 shows the emission current response of a $\mathrm{W} / \mathrm{BaCaAlO}$ film as a function of the square root of the applied field (Schottky format). A Schottky format is used to extract zero applied field current density values as a function of temperature. These values are used to determine the work function and apparent emission coefficient using the Richardson-Dushmann equation, provided emission is stable over the temperature range investigated. The rapid transition to a linear response for these curves at relatively low fields (above 200 


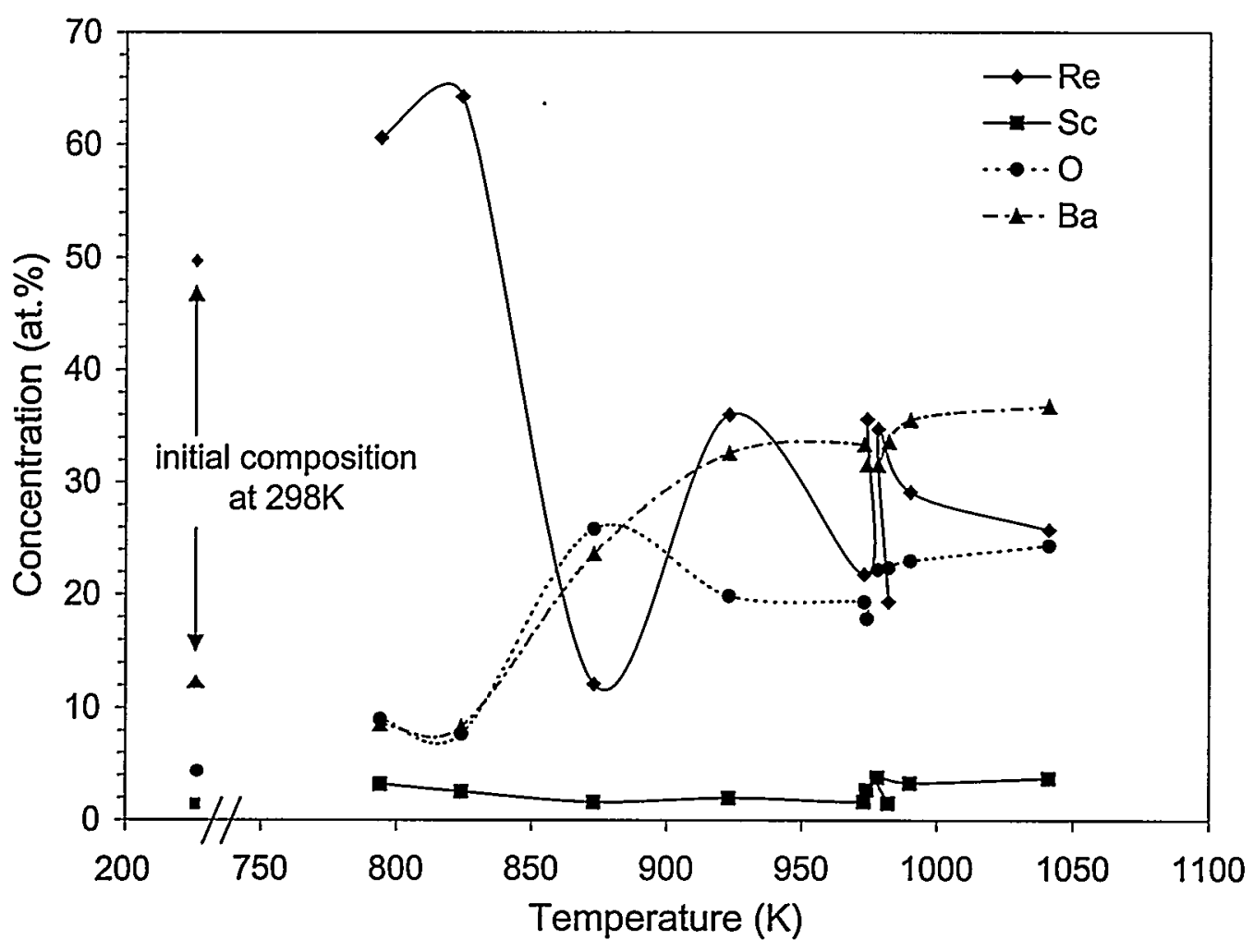

FIGURE 3. Variation in near surface composition of $\mathrm{Re}, \mathrm{Sc}, \mathrm{O}$, and $\mathrm{Ba}$ as a function of annealing temperature. Composition measured by Auger electron spectroscopy at the indicated temperature for a $10 \mathrm{~nm} \mathrm{W/20} \mathrm{nm} \mathrm{BaCaAlO}$ modulated film with a $3.5 \mathrm{~nm} \mathrm{Re} / 2 \mathrm{~nm} \mathrm{Sc}_{2} \mathrm{O}_{3}$ terminal layer.

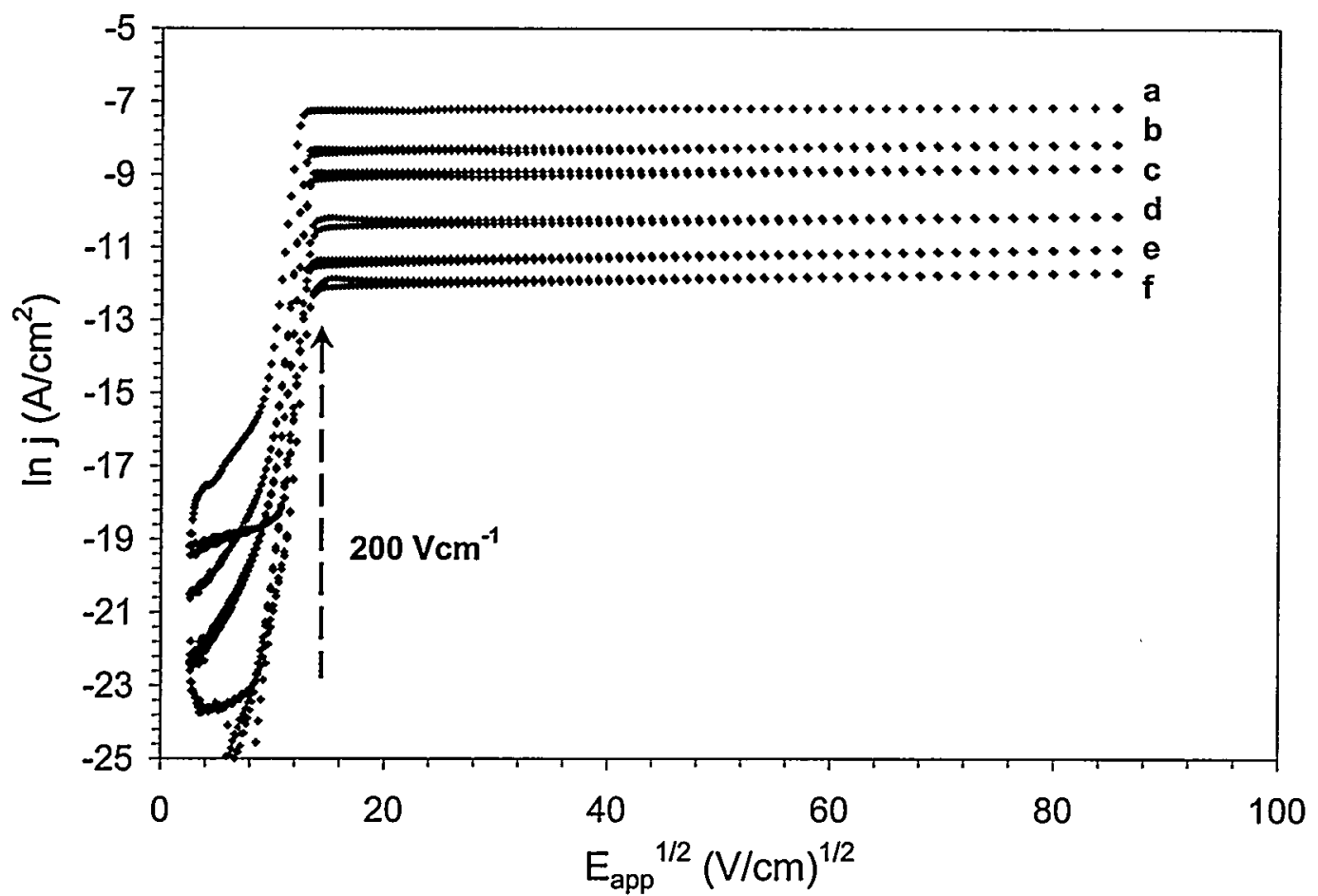

FIGURE 4. Schottky plot showing the variation in emission current from a $10 \mathrm{~nm} \mathrm{W/20} \mathrm{nm} \mathrm{BaCaAlO}$, modulated film with a $3.5 \mathrm{~nm} \mathrm{Re} / 2 \mathrm{~nm} \mathrm{Sc}_{2} \mathrm{O}_{3}$ terminal layer as a function of applied field for various temperatures - a) $\left.\left.1061 \mathrm{~K}, \mathrm{~b}\right) 1003 \mathrm{~K}, \mathrm{c}\right) 973$, d) $939 \mathrm{~K}$, e) $934 \mathrm{~K}$ and f) $921 \mathrm{~K}$. 
$\mathrm{V} \cdot \mathrm{cm}^{-1}$ ) indicates saturated emission, a true Schottky response and no discernable space charge. A sharp transition is observed in the emission current at a field of $200 \mathrm{~V} \cdot \mathrm{cm}^{-1}$. This field marks the point at which the collector work function becomes less than that of the modified emitter (due to the applied field) and no further electrostatic barrierwithin the inter-electrode gap exists as a restriction toward electron flow. The fact that the transition is so sharp indicates a uniformly emitting surface with a narrow energy distribution for the work function. This property would be expected for a Re metal surface covered by a uniform $\mathrm{Ba} / \mathrm{O}$ surface complex. Unfortunately, a work function and apparent emission coefficient cannot be extracted from the data of Figure 4 due to instability in electron emission as the surface composition and structure apparently evolve over this temperature range.

Emission becomes sufficiently stable with annealing to a temperature of approximately $1200 \mathrm{~K}$. Analysis of emission data generated with annealing to $1200 \mathrm{~K}$ yield a work function of $2.2 \mathrm{eV}$ and an apparent emission coefficient of 6 $\mathrm{A} \cdot \mathrm{cm}^{-2} \cdot \mathrm{K}^{-2}$. These values compare to a $1.4 \mathrm{eV}$ work function and an apparent emission coefficient of $7 \mathrm{~A} \cdot \mathrm{cm}^{-2} \cdot \mathrm{K}^{-2}$ found for a $\mathrm{Re} / \mathrm{Sc}$ modified macro-dispenser cathode (Gärtner, 1997). The Re surface concentration is reduced to less than 5 at.\% at these higher temperatures and the emission curves lose their sharp, low field transition point. The combination of this moderately low, distributed work function and the surface Re loss indicate that at $1200 \mathrm{~K}$ these films are converted to essentially oxide cathodes.

The high value of the apparent emission coefficient is a favorable property producing significant current density at moderate temperatures. This film can be used to produce small levels of power by relying on only the emittercollector work function difference across a small gap spacing. Figure 5 shows the results of a current density measurement with time for a zero applied field using a Ba coated Mo collector. A value of as great as $8 \mathrm{~mA} \cdot \mathrm{cm}^{-2}$ is measured at $1200 \mathrm{~K}$ for a gap spacing estimated at $100 \mu \mathrm{m}$. We estimate the emitter-collector work function difference to be $1 \mathrm{eV}$ indicating that milliwatts of power are being generated.

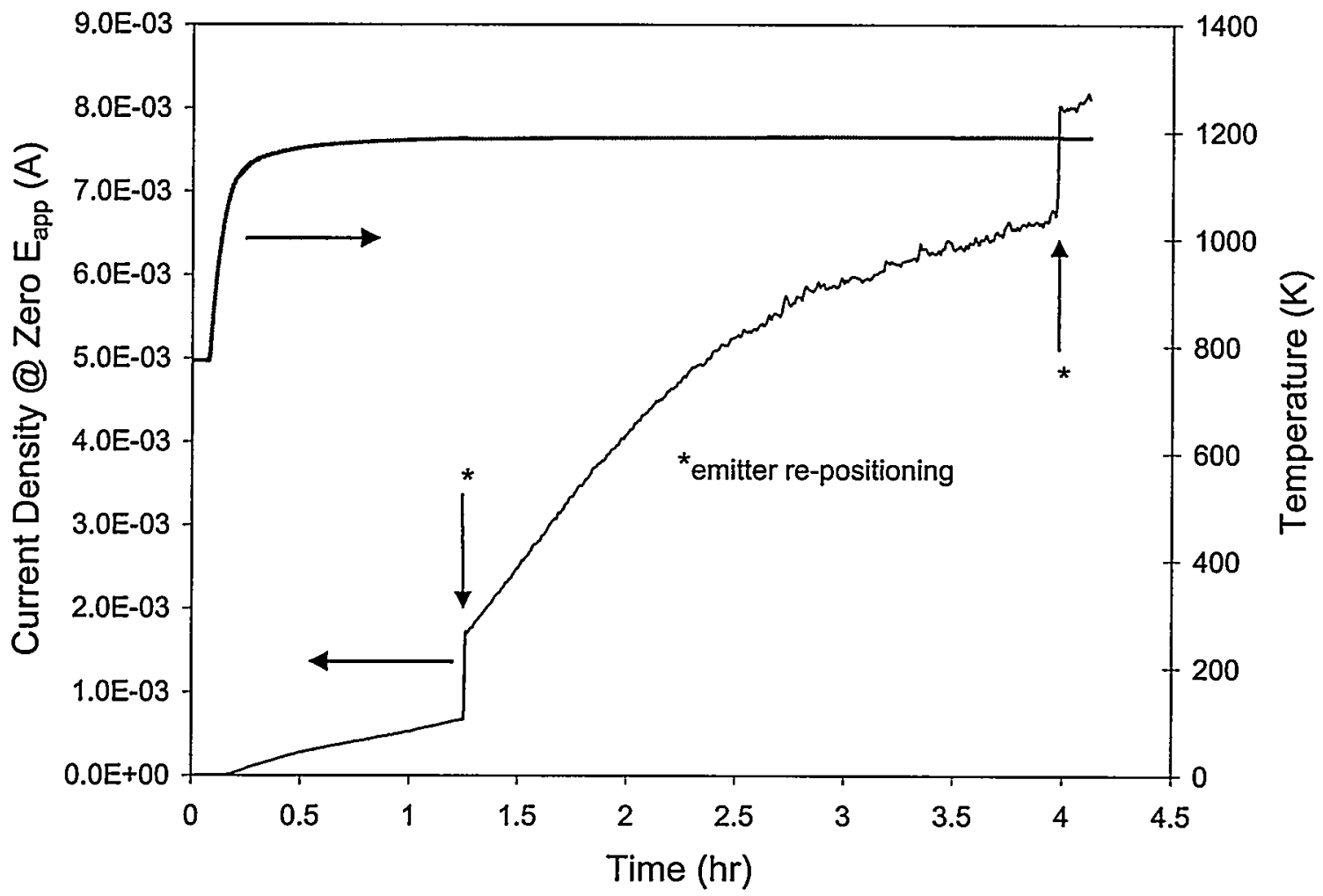

FIGURE 5. Maximum diode current density measured for a $10 \mathrm{~nm} \mathrm{W/20} \mathrm{nm} \mathrm{BaCaAlO}$ modulated film at zero applied field. The discontinuities in current density are a result of gap adjustments to eventually produce an approximate $100 \mu \mathrm{m}$ spacing between emitter and collector. 
Some degree of tailoring the film structure at elevated temperatures appears possible. Characterization of a series of $\mathrm{W} / \mathrm{BaCaAlO}$ films shows that the annealing temperature and integrated time at temperature where the uniform $\mathrm{Re}$ surface layer is lost is variable. A continuous Re layer is observed at temperatures of $1180 \mathrm{~K}$, for some samples. In addition, attempts to add activators (specifically $\mathrm{C}$ ) to facilitate $\mathrm{Ba}$ reduction and transport through the film bulk yield surfaces that retain a uniform Re coating to a temperature of $1300 \mathrm{~K}$. Atomic force and secondary electron microscopy show that these films also maintain their original morphology. Scanning Auger images show that $\mathrm{Ba}$ exists from the bulk of the film at a low density of small sites distributed across the surface and then diffuses laterally across the surface. Coupling these characteristics with utilization of $\mathrm{Sc}$ in the emitting surface complex suggests that films possessing a homogeneous work function as low as 1.2 to $1.4 \mathrm{eV}$ may be achievable with film tailoring (Zagwijn, 1997).

\section{CONCLUSION}

Our results show that a thin film dispenser or micro-dispenser cathode can be generated using standard deposition technology. Measurements shows that stable emission is produced from a moderate work function, high apparent emission coefficient surface. Preliminary emission measurements of these films using a barium covered Mo collector show that current densities of $8 \mathrm{~mA} \cdot \mathrm{cm}^{-2}$ can be achieved at $1200 \mathrm{~K}$ and zero applied field. This demonstration of energy conversion relying only on an emitter-collector work function difference is the first step in developing a film suitable for a moderate temperature, miniature diode. We envision the use of this type of film in Sandia's Microminiature Thermionic Converter (MTC) diode producing milliwatt and greater power levels. Our deposition methodology allows for the flexibility to further tailor the structure/composition and optimize the emission properties of this type of film. Ideally, a much lower work function in the 1 to $1.2 \mathrm{eV}$ range is desirable while maintaining a relatively high emission coefficient. Our current focus is on optimizing emission from these films by tailoring the deposition process.

\section{ACKNOWLEDGMENTS}

The work presented in this paper was conducted under the sponsorship of the U.S. Defense Threat Reduction Agency (DTRA) and Department of Energy (Nuclear Energy). David Fein (Sandia National Laboratories) provided technical assistance. SNL is a multi-program laboratory operated by Sandia Corporation, A Lockheed Martin Company, for the United States Department of Energy under Contract DE-AC04-94AL85000.

\section{REFERENCES}

Gärtner, G., P. Giettner, H. Lydtin and A. Ritz, "Emission Properties of Top-Layer Scandate Cathodes Prepared by LAD," Appl. Surf. Sci. 111(1997) 11-17.

Gibson, J.W., G.A. Haas and R.E. Thomas, "Investigation of Scandate Cathodes: Emission Fabrication and Activation Processes," IEEE Trans. Electr. Dev., 36(1), 1989, 209-214.

King, D.B., K.R. Zavadil, J.A. Ruffner and J.R. Luke, Proc. $35^{\text {th }}$ Intersociety Energy Conversion Engineering Conf., AIAA-2000-2844, July, 2000.

Thomas, R.E., J.W. Gibson, G.A. Haas and R.H. Abrams, "Thermionic Sources for High-Brightness Electron Beams," IEEE Trans. Electr. Dev., 37(3), 1990, 850-861.

Zagwijn, P.M., J.W.M. Frenken, U. van Slooten, and P.A. Duine, "A Model System for Scandate Cathodes," Appl. Surf. Sci., 111, 1997, 35-41. 